\title{
VIRTUAL FACTORY AS AN ADVANCED APPROACH FOR PRODUCTION PROCESS OPTIMIZATION
}

\author{
Debevec, M.; Simic, M. \& Herakovic, N. \\ Laboratory for Handling, Assembly and Pneumatics, Faculty of Mechanical Engineering, \\ University of Ljubljana, Askerceva 6, SI-1000 Ljubljana, Slovenia, EU \\ E-Mail: miha.debevec@fs.uni-lj.si,marko.simic@fs.uni-lj.si, niko.herakovic@fs.uni-lj.si
}

\begin{abstract}
This paper demonstrates a new methodology for designing a virtual factory model and model execution on the basis of a real schedule plan. The main characteristic of the developed method is that the inputs are regarded as one of the main parameters of the production process, and the main objective is to create a low-cost production process model. The methodology is adjusted for use in SMEs (Small and Medium-Sized Enterprises) with individual or unique type of production. For such companies, the method represents an ability to optimize existing production processes through detecting and eliminating possible errors and disturbances before the real production process is executed at an acceptable cost. The applicability and suitability of the developed method for virtual production performance has been proven with the verification process, where the input data for the simulation was obtained from a real company. The simulation results have shown that the presented methodology is a useful tool for the optimization of the production process.

(Received in June 2013, accepted in September 2013. This paper was with the authors 1 month for 1 revision.)
\end{abstract}

Key Words: Virtual Factory, Unavailability of Resources, Modelling, Simulation, Optimization

\section{INTRODUCTION}

In today's market, SMEs are quite a frequent company form. If they want to be successful, they must be capable of adapting instantly to the new and often changeable market demands. They must be able to quickly organize their production and the flow of resources in a unique and small quantity production as best as possible. Only that kind of work keeps them globally competitive, successful and innovative.

Researches of production times in smaller companies indicate that machining and assembly actions of each operation represent only $5 \%$ of the entire operation duration. The other $95 \%$ of the operation time represent the placing of physical resources at the preliminary operations or the waiting before the next operations during setup times. Much of the operation time is also unnecessarily spent on transportation and handling etc. [1].

Different research studies indicate the enormous loss of production time in machining, handling and assembly operations, caused mostly by the unavailability of resources [2]. From practical experience, it is well known that the right quantity of the right resources at the right time and in the right place is one of the most important factors and even a precondition for the start of every individual operation.

If SMEs want to eliminate the non-availability of resources, they should detect and eliminate the majority of possible mistakes and disturbances in advance and in this way they could avoid the majority of deadlocks in the production process.

As a result of our research work, an advanced method was developed for verifying the planned schedule with emphasis on the presence of the required resources. On the basis of the developed method, an example of a low-cost pilot simulation model was created. Development of a low-cost simulation tool was the objective of various researches, with the goal that the simulation would be accessible to small businesses with small batch production 
that want to improve their manufacturing processes. For this reason, the virtual factory is a suitable environment in which the developed simulation models are carried out.

The paper presents the verification for the developed method and simulation models which proves the practical applicability of the proposed method for small companies with an individual or small quantity type of production.

\section{VIRTUAL FACTORY AND VIRTUAL PRODUCTION}

In general, virtual production is defined as the integration of different models, simulations and presentation techniques in an integrated system on a computer that allows the execution of the production plan in a virtual environment or, in other words, the performing of the production process in a virtual factory $[2,3]$. For the successful introduction and implementation of the virtual production it is necessary that the company successfully uses the integral information system which supports each stage of the production process [4].

In today's demanding market, it is particularly important for SMEs to constantly upgrade and improve their operation and thus stay successful. Based on past research [1], it is clear that there are significant reserves in the production process organization. The optimization can be carried out in the following ways:

- scheduling the production operations in time scale [5-8], which is the most common approach in practice,

- improvement of the production process at the level of the operation's execution [3, 9-13] and

- special approaches to improve production effectiveness [14-18].

There are several simulation tools on the market that make production process optimization possible [2]. Most computer simulation systems, commonly known as Digital Factory [19], are designed for use in large-scale and mass productions. They are practically inaccessible for smaller companies because of the very high prices of such virtual production systems [2].

Compared to the real production process, the biggest advantage of virtual production is that in virtual environment we operate only with data and not with physical resources, materials, and energy [2].

The production process in a virtual environment can be performed in any number of experiments and under various conditions and before the planned production processes are performed in actual production [2]. The analysis of the production process parameters is carried out based on the results of virtual production and on the basis of those results the optimization of the production plan is carried out.

\section{DEVELOPED METHOD FOR VIRTUAL PRODUCTION}

The developed method for virtual production performance was based on the findings from literature [2,9] and practical experience. The method is called PoVEIR (Production in Virtual Environment Incorporating Resources) and has been designed especially for the optimization of the production processes in smaller companies which are characterized by a unique, smallscale and variable production volume.

One of the fundamental directions in the method development process was that the planned production process which is determined by a schedule plan is carried out in the same way on the computer as it would be performed in the actual production process. For this reason, the real production system (Fig. 1) is mapped out on the computer with a precision that provides satisfactory results of the virtual production. 


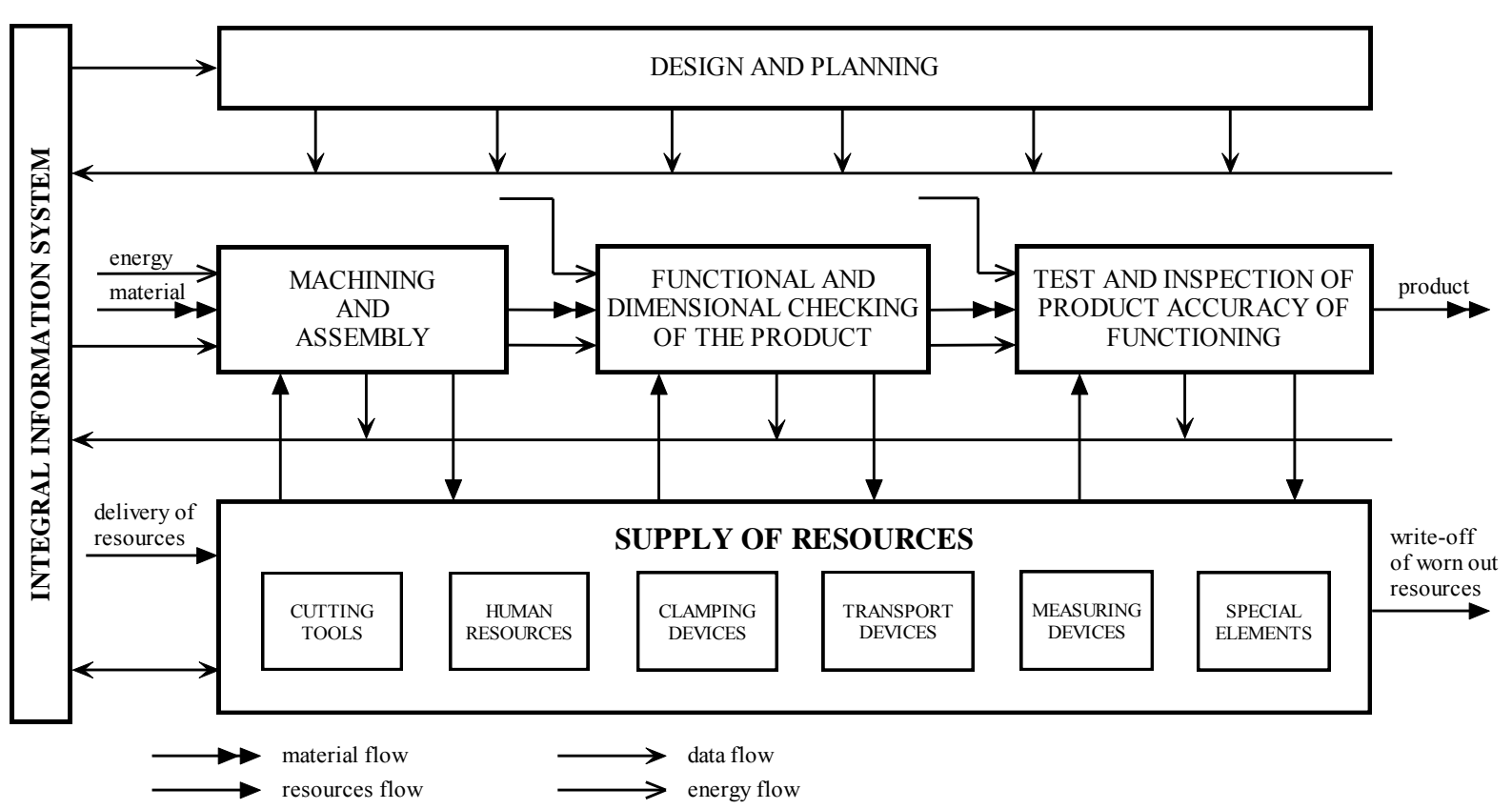

Figure 1: Material and data flow in the production company from a cybernetic point of view.

The most important part of a real production system that is used in a virtual production system is the data about the real production process. All the data for the entire production system are managed and controlled by the integral information system (Fig. 1). It also manages the data about how the production and assembly processes should be performed and which conditions must be met for the execution of the production process. The integral information system also supports resource management, which ensures an appropriate quantity of all the required resources in the entire production process.

The PoVEIR method is designed as an advanced approach which, as opposed to the standard systems for virtual production, takes into account the presence of the significant physical and human resources in the execution of every basic part of the production process.

The results of a virtual production execution could be used for predicting how the actual schedule plan will be carried out in a real production system in the future. By changing the set of resources or the availability of resources we obtain feedback about the execution of the production process according to the schedule plan. In this way it is possible to predict various unexpected delays that occur due to the unexpected unavailability of the required physical and human resources.

\subsection{Building the model of a virtual factory}

The essential idea in the innovative PoVEIR method is that the virtual factory is created as a combination of (Fig. 2):

- the virtual physical system and

- the real information system.

The virtual physical system is built on the basis of actual data from a real production system and has all the essential features of the actual production system. The most relevant data collections about a production system are the data about the real production system layout and the logical interdependence between different elements of the production system. A real information system is obtained through data connections with a real database. Physical and information systems are connected via communication links in order to mutually exchange data. For the virtual production performance, the same input data are used as the 
input data for the real production. And finally, the PoVEIR method ensures that the output data of the virtual production are comparable with the output data of a real production. This confirms the hypothesis that virtual production is comparable to real production performance.

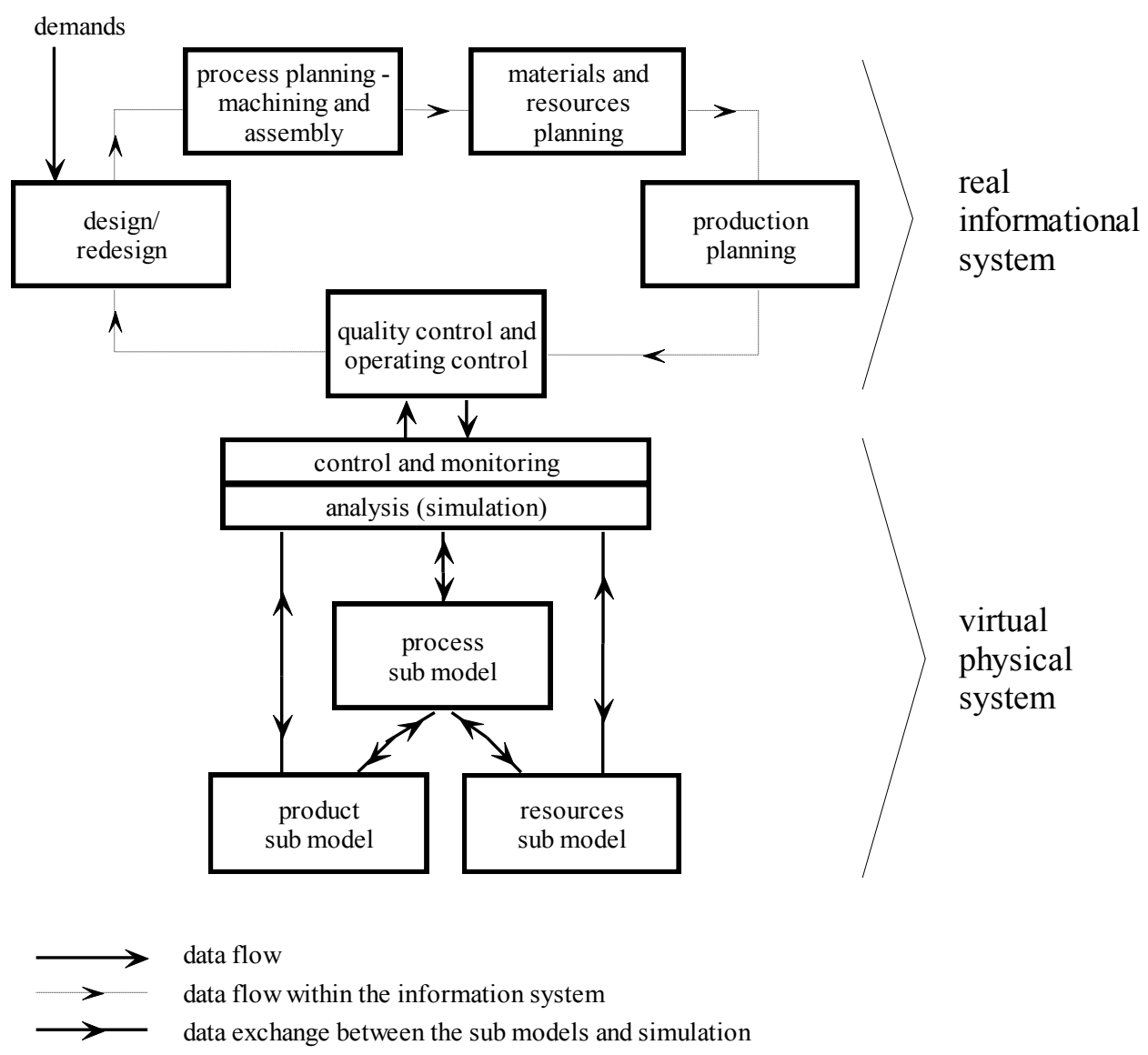

Figure 2: Data flow scheme in the virtual factory.

The model of the virtual physical system that authentically describes a real production process (Fig. 3) is based on the characteristics of a typical representative of a small company with a unique quantity type of production. The virtual physical system is created as a combination of three sub models which are mutually interconnected and intertwined:

- product sub model,

- process sub model,

- resources sub model.

The product sub model represents all the types of products in the observed time period and the process sub model comprises all the variants of processes that can be carried out in the observed time period and are defined in detail. The resources sub model contains all the data about the resources in the production process and the data about the production process structure (factory structure). Those data are the data about the production system layout and the logical dependences between all the physical elements of the production system.

It is commonly known that all input conditions must be available for the execution of the production process. This means that the production process can be performed when all input conditions (Fig. 3 and Table I), such as NC programs, time schedule data, technological/ operational lists, data about all the resources, energy, physical resources, human resources, and machining parts, are present at the place of implementation of the production process. 

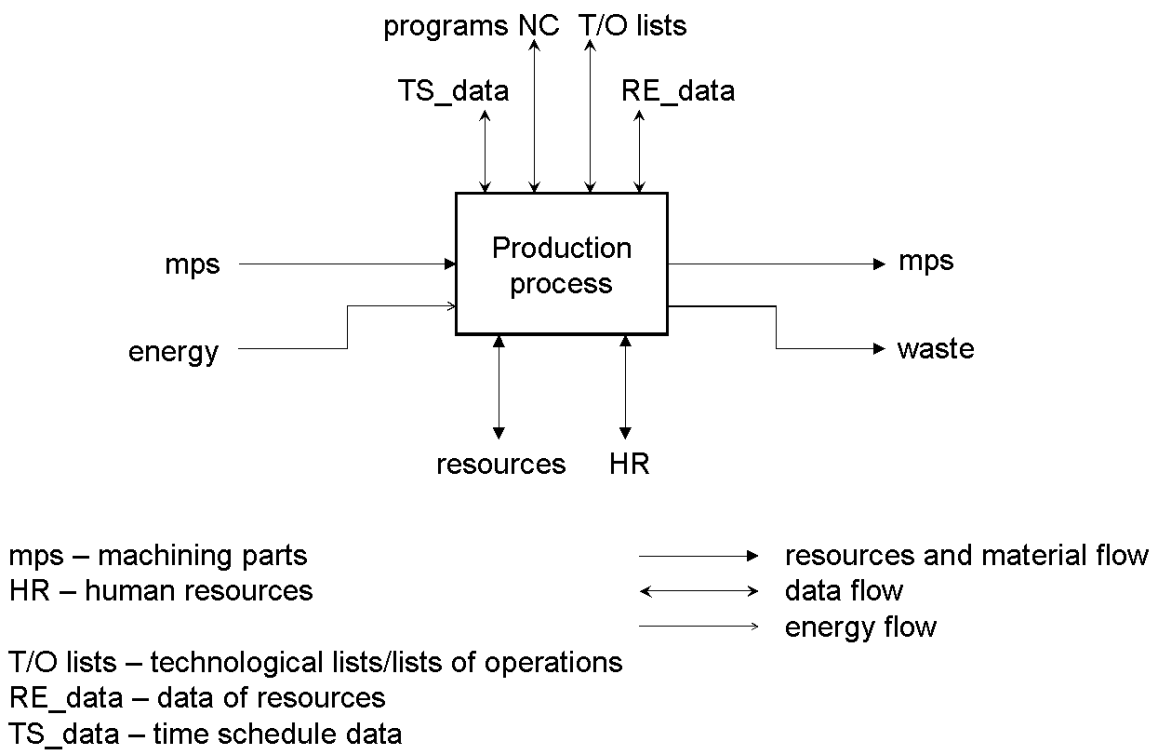

Figure 3: Inputs and outputs of the production process in typical small companies with unique and small quantity type of productions.

Table I: Description of inputs and outputs of the production process.

\begin{tabular}{|l|l|}
\hline Production factor & Description \\
\hline programs NC & $\begin{array}{l}\text { numerical control programs for operations execution on machining } \\
\text { centres (or working centres or assembly centres etc.) }\end{array}$ \\
\hline time schedule data & time schedule data about operations executions in time scale \\
\hline $\begin{array}{l}\text { technological/operational } \\
\text { lists }\end{array}$ & documents which contain technological and operational data \\
\hline data of resources & data about all the resources in the production system \\
\hline resources & the required physical resources for the production process \\
\hline human resources & the required human resources for the production process \\
\hline machining parts & $\begin{array}{l}\text { machining parts (or working or assembly parts) in the production } \\
\text { process }\end{array}$ \\
\hline energy & all types of required energy \\
\hline
\end{tabular}

The production process execution for every machining part is defined by the combination of the product sub model and the process sub model. The production process execution for every machining part actually consists of a sequence of operations [20] that is defined in the technological plan. For every operation, it is determined which inputs are required to start performing the operation (Fig. 4).

According to the PoVEIR method, the operation is a basic element of the production process and it is defined as part of a technological process performed by one employee or a group of workers at one workplace with one working machine and by using different tools and/or devices. In this context, the expression level of operation also appears and it is defined as part of the operation which is carried out at one workplace with one tool at one clamping [21]. Within an individual order, the number of ordered products represents the number of cyclical repetitions of the operation [22].

It is considered that the performing of every individual operation can start when all the input conditions (Fig. 4) are present at the required time, at the required place and in the required quantity. 

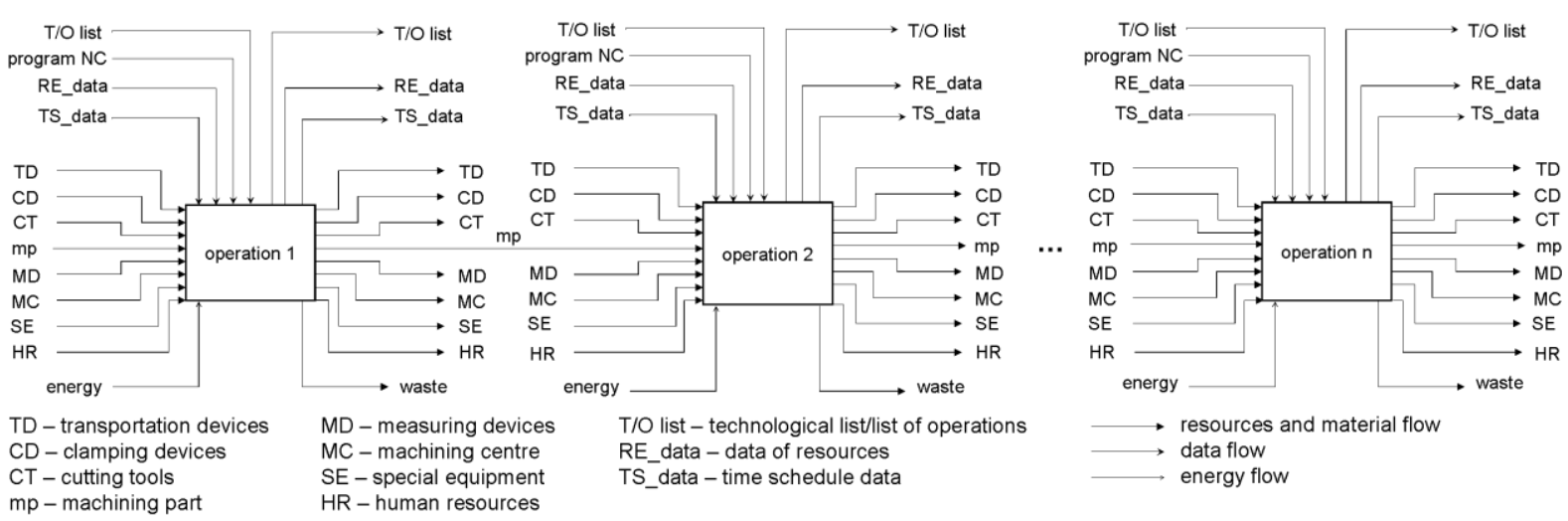

Figure 4: Inputs and outputs of the operations in the production process and an example of the sequence of the performing of operations.

\subsection{Resources in the virtual factory}

All the resources in the production system are identified in the resources sub model. For this purpose it is required that the database in a company must contain all the key data about each resource.

The most important resources in the production system are (Fig. 4):

- machining centres (or working centres or assembly centres etc.),

- cutting tools,

- clamping devices,

- transportation devices,

- measuring devices,

- special equipment and

- human resources.

Each individual physical resource has to be characterized by all the parameters that are required from the model. Therefore, each individual physical resource must be characterized by at least the basic characteristic parameters such as the ID number, the location, availability, and availability schedule.

\section{LOW-COST VIRTUAL FACTORY}

The virtual factory with included simulation model is focused on the importance of the presence and availability of the production resources in the production process. The presence and availability of all the demanded resources is a condition for every single operation to be performed. The human resources in this part of the study are accounted as resources that are available during the working time periods. At this stage of the research, the psychological factors, sociological factors, and the possibility of decision making are not taken into account and modelled for human resources.

On the basis of the PoVEIR method, a pilot low-cost simulation model was developed. It consists of four significant parts (Fig. 5):

- the model of the production system,

- production process data,

- the module for setting up the environment for simulation and execution and

- the module for the presentation of simulation process results. 


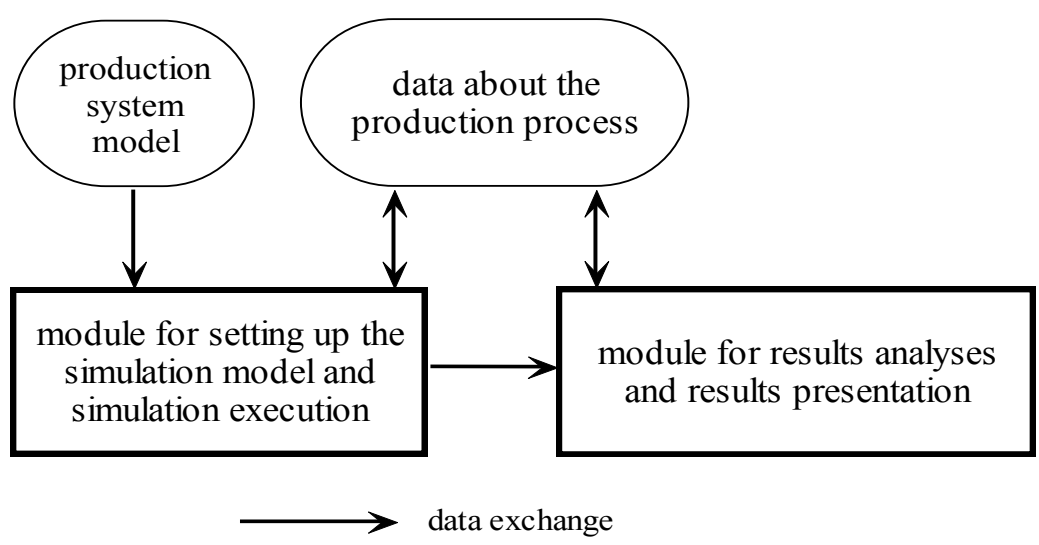

Figure 5: The functional parts of a pilot model based on the PoVEIR method.

\subsection{Production system model}

The production system model is built on the basis presented in section 3.1, and describes a real production system with the required precision down to the level of operation. The model contains the production process elements of the entire production system and also comprises the logical connections between them in a way that makes the execution of the model on a computer possible.

For the production system model and the simulation execution the resources sub model is the most important. It is understandable that the production process execution for a defined period requires accurately defined resources. The list of required resources is simply acquired from the schedule plan. With the combination of the list and the data structures of all resources in the production system we actually create a dynamic resources model for a defined time period.

In the research context, it is appropriate to use a discrete event simulation technique for performing a simulation of the production system. Discrete event simulation means that events are observed only at the time when any of the characteristics of the elements or processes in the production system are changed. This feature of the discrete event simulation has the significant advantage of a shorter simulation time.

On the basis of the discrete event theory [23-25], the factory layout design was designed like an extended Petri net graph (Fig. 6). The extended Petri net graph is constructed on the basis of an analogy with the activities graph (Fig. 4). Based on this theory, every single operation in the production process is defined as a transition between two states. Each transition can be performed when all the input places are full and those places are essentially the input conditions. Thus, the input places of each activity are understood as the conditions of the activity, and the output places as the result. The following operation can begin only after the previous operation is completed.

The sequence of operations for each working centre represents a logical and chronological sequence which is the sequence of operations in an individual working centre during the production process (Figs. 4 and 6). The sequence of operations is generated from the schedule plan.

\subsection{Production process data}

For virtual production, the appropriate data structure is required and the data must characterize the production process, all the products, and all the resources in the system. The data are obtained from an integrated information system through queries in proper structure. 
In general, these data are the code, name, location, ID number, and the information about the availability of each element.

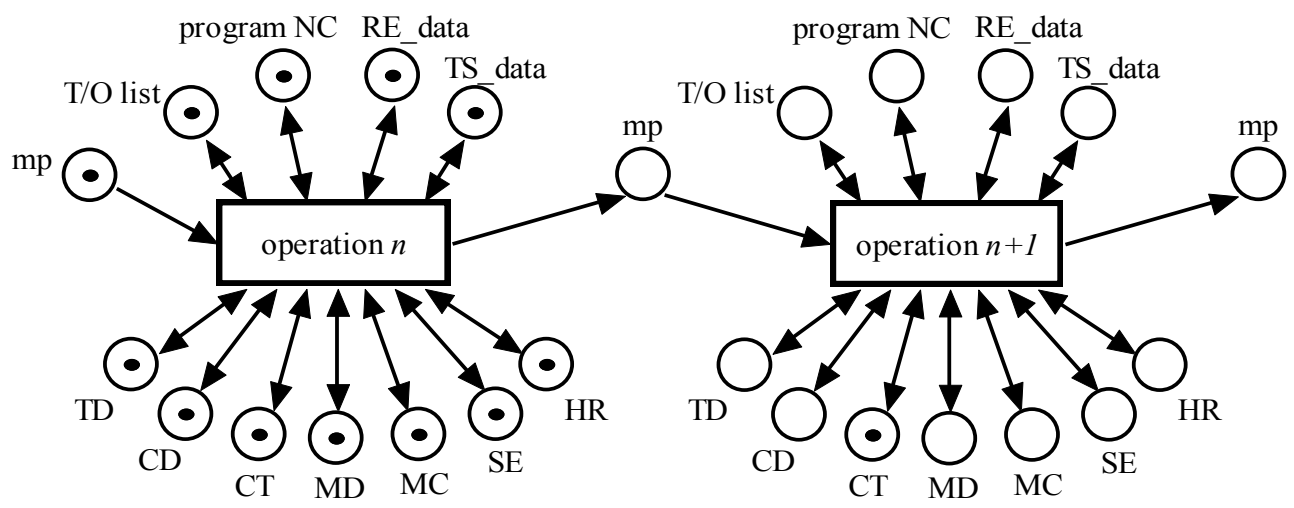

$$
\begin{aligned}
& \text { TD - transportation devices } \\
& \text { CD - clamping devices } \\
& \text { CT - cutting tools } \\
& \text { mp - machining part } \\
& \text { MD - measuring devices } \\
& \text { MC - machining centre }
\end{aligned}
$$

SE - special equipment

HR - human resources

$\mathrm{T} / \mathrm{O}$ list - technological list/list of operations

RE_data - data of resources

TS_data - time schedule data

Figure 6: An example of Petri nets based on the activities graph.

Furthermore, the schedule data are required. This determines the sequence of the operations that are planned in sequence to carry out the production process. For every single operation from the schedule data the required resources for its execution are specified. There are also the specified data about what, where, when, who, and how the operation will be carried out. From the working centre point of view, the schedule data is the working plan for the production process for a specific time period.

\subsection{Setting up the simulation model and simulation execution}

The virtual factory simulation model is based on the PoVEIR method and is designed in a standard computer tool Plant Simulation (Tecnomatix eM-Plant) (Fig. 7).

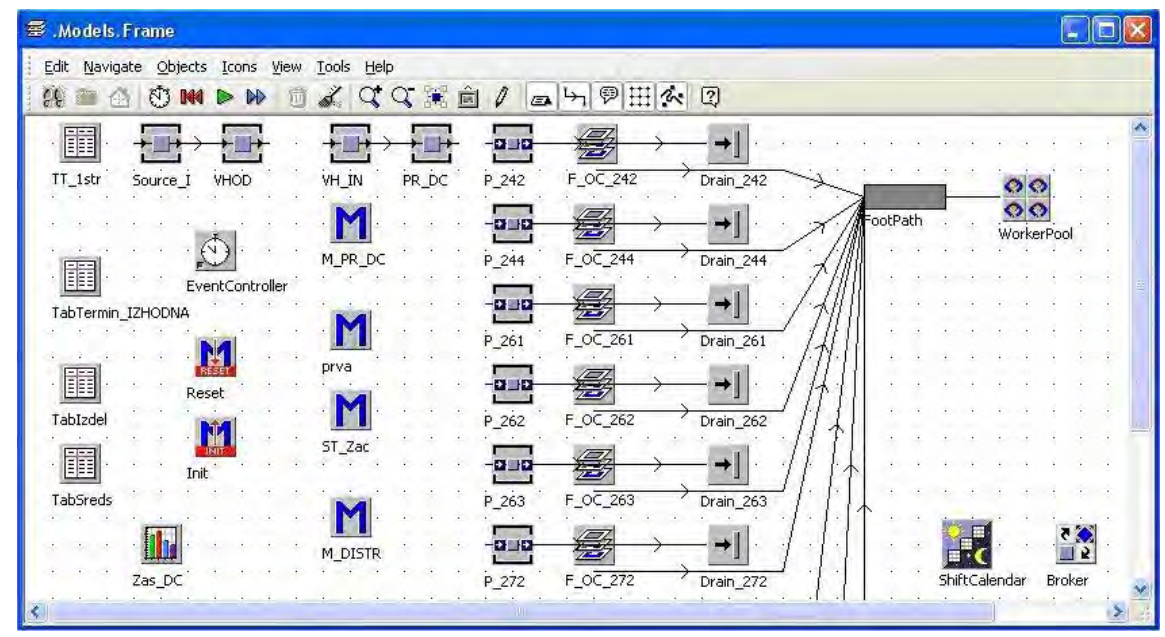

Figure 7: An example of the virtual factory in Plant Simulation.

The simulation runs are also executed in that tool. This standard simulation tool has been used for several reasons and advantages: 
- the simulation tool is based on discrete events execution,

- the tool is a standard and generally applicable simulation tool,

- the program is object-oriented,

- data exchanges between the simulation model and databases are not complicated,

- the complex logical dependencies in the production system can be modelled by programming in the programming language SimTalk [26],

- the simulation tool is suitable for making simulations for the production process of small companies with small batch or unique type of production,

- the tool offers an easy way to create different and desired graphical or numerical presentations about the progress of the production process in a virtual factory.

The simulation model of the production system is designed in a way that the production parameters in the model are adapted automatically in real-time according to the data from the schedule plan.

\subsection{Simulation process results}

The virtual production performance in a virtual factory uses the schedule data for the future as input, and as output we obtain the data about the expected state and progress of the production process in the future. In this way we obtain the data about the predicted times through the simulation for every single operation:

- the start of operation,

- the completion of operation and

- the estimated duration of operation - lead time of operation.

The acquired data are compared to the input schedule data, and after comparing the data it is determined whether the output data is satisfactory regardless of the schedule plan for the production process in the future. If the result of the analysis is unsatisfactory, the schedule should be corrected appropriately and the fine planning of the production process should be repeated. The modelling, simulation, and evaluation of the results should be done again.

The obtained results demonstrate the comparison between the schedule and the results of the virtual factory and must be presented clearly to the users. The most suitable presentation is graphical.

\section{VIRTUAL FACTORY: VERIFICATION AND EXECUTION}

The virtual factory developed on the basis of the innovative PoVEIR method was tested with the verification process to prove its relevance and applicability. Verification was performed by a comparison between the outputs of the virtual production and the post-calculation data from a real production process. In both cases the same input data were used. The postcalculation data have been obtained from the database of a real company for the observed time period. The verification was performed for several cases or, more precisely, for one working centre, two working centres, and nine working centres. The same production parameters were used in the virtual factory as in the real production.

The verification process has revealed that the acquired simulation results regarding production times coincide with the post-calculation production times within the range of 1 to $1.2 \%$. This clearly shows that virtual production in the virtual factory is a suitable and applicable tool for the prediction of a production process.

Furthermore, it was also discovered that internal transport times for the observed type of production can be disregarded because these times represent about $0.5 \%$ of the total 
production time. These times, compared to the waiting times in the production, represent a very small effect on the total production time.

The simulation results comprise all the principal data which determine the sequence of the production process in the virtual factory. These data are:

- the code of the work piece,

- the ID number of the operation,

- the code of the working centre where the operation is executed,

- the start time of every operation,

- the completion time of every operation in virtual factory,

- the duration of an operation in virtual factory, etc.

The most important data from the virtual factory about every single operation are the start and the completion time of an operation, and the subtraction between those times that represents the duration of the operation. A comparison and analysis is carried out for the obtained operation times and the data from the schedule. If there are no significant deviations between the compared data, the schedule is ready to use in a real production. If deviations occur, it is necessary to find the causes, remove them, and re-plan the production process. A new simulation in the virtual factory is then performed with the corrected and optimized schedule. These steps can be repeated until the optimal schedule plan is achieved.

The verification of the virtual factory for production on one machining centre in the toolshop has been carried out to confirm the presented method. A comparison was made between the planned hours and the hours it took for a production process to be performed in the virtual factory (Fig. 8). In the first column (Fig. 8, Run 1), the deviation between the planned data and the simulation results data is evident. After an analysis, we discovered that deviations occurred because of the unavailability of resources during the production process. Alternative resources were then put in the schedule and the simulation was run again. In the second column (Fig. 8, Run 2), it is evident that the differences between the planned data and the simulation results data are no longer significant and the corrected schedule is appropriate to use in a real production process.

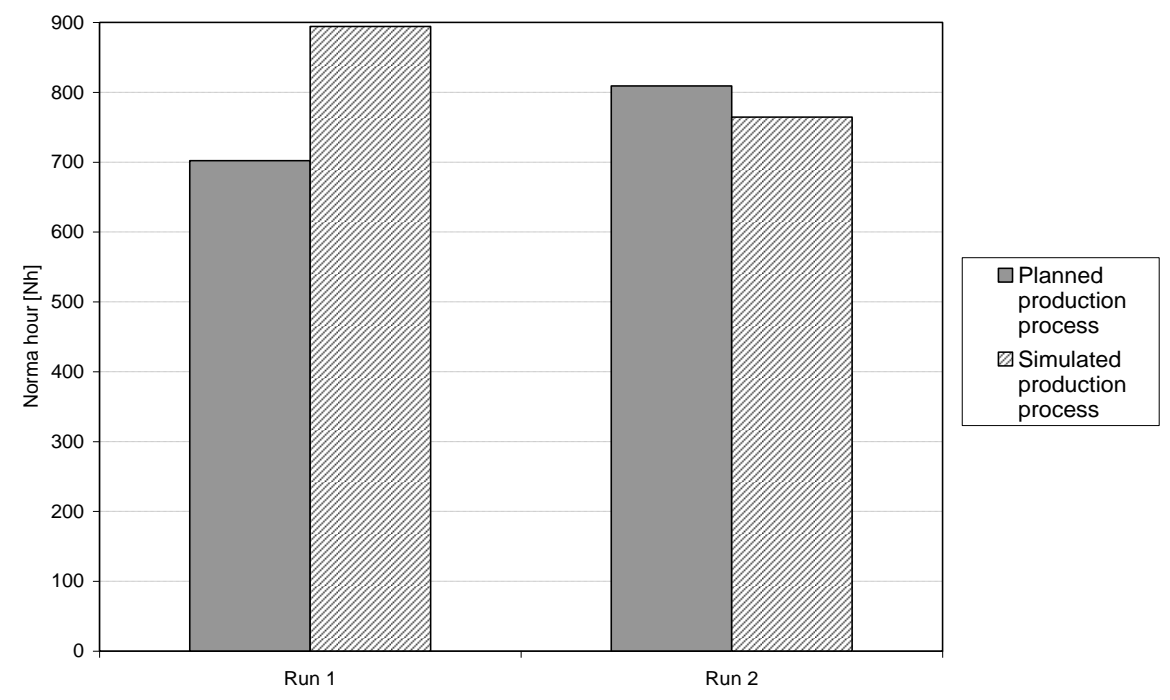

Figure 8: Comparison between the planned data and the simulation results data for one working centre.

Another example shows the analysis between the planned data from the schedule plan and the results of the simulated production process for nine working centres (Fig. 9). In the same chart, two runs for each working centre are compared. First runs represent the comparison 
between the planned schedule data and the simulation data from the virtual factory. Because of the deviations in the first run, corrections were made in the production plan and schedule. The simulation was then performed again in run two. The comparison between the corrected schedule plan and the obtained data from the simulation shows that deviations are much smaller than in the first run (Fig. 9, Run 2). Based on the obtained results, we can say that the corrected schedule is suitable for use in a real production.

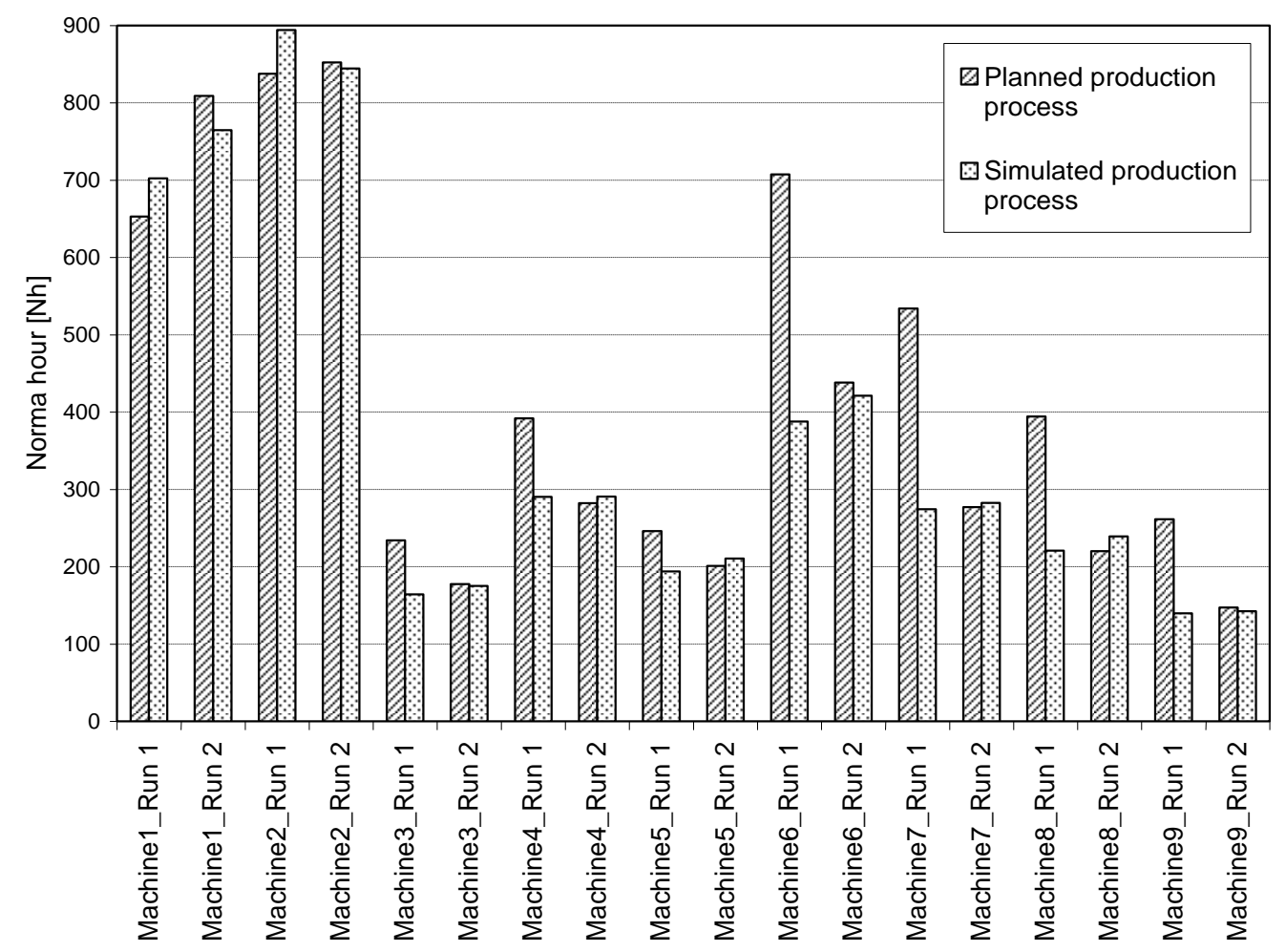

Figure 9: Comparison between the planned data and the simulation results data for nine working centres.

The simulation of the production process facilitates the production times monitoring, but also the detection of failures, congestions, unavailability of resources, and defects in a planned production process. In practice, the virtual factory approach is suitable because it enables fast performing of a planned production process that depends on various production process parameters, such as the number of workers in a shift or the number of shifts. Another very important characteristic of the virtual production is the fast obtaining of the information about the expected completion of the schedule, which is very useful for rough production planning.

\section{CONCLUSION}

This paper presents the innovative approach PoVEIR. It is based on the execution of a virtual production in a virtual factory and is focused on the presence of resources in the production process execution. The main advantage of a virtual production is a simple and fast execution of the production process simulation at low cost. The developed approach is most suitable for use in small companies with the small quantity type of production.

The verification for the virtual factory has been carried out and it has been demonstrated that the new simulation approach is suitable for practical use. The virtual factory has been verified for a period of time in several steps, first for one work centre and then for a group of 
work centres. The input data for the simulation were obtained from a real test company. The comparison of the data acquired from the virtual production and the data from postcalculation showed their proper matching which verifies the suitability of the new PoVEIR approach.

The applicability of the virtual factory is clear from the presented example. For the production process with nine machining centres, it is evident that in Run 1 the planned production process times and the simulated production process times differ on average by $30 \%$. After correcting the schedule plan and re-performing the simulations in Run 2, the times differ on average by only $4 \%$.

And finally, with special upgrades, the developed virtual factory could be applicable in other types of companies with small quantity type of production. Further research in the virtual factory field should be focused on upgrading the model with the integration of human resources decisions for the cases where the production process is not precisely defined.

Virtual factory is also useful in education and training. It offers students and employees a simple way to perform tests and studies of various production scenarios and to observe the response of the virtual factory to the input data. In this way, they quickly and easily acquire the knowledge and experience regarding the behaviour of the observed production system.

\section{REFERENCES}

[1] Nyhuis, P.; Wiendahl, H. P. (2009). Fundamentals of Production Logistics: Theory, Tools and Applications, Springer-Verlag, Berlin

[2] Debevec, M. (2010). Modeling of Tools Handling in Manufacturing for Digital Environment, Ph.D. Dissertation, University of Ljubljana, Faculty of Mechanical Engineering, Ljubljana

[3] Savarese, A. B. (2011). Manufacturing Engineering, Nova Science Publishers, Inc., New York

[4] Chryssolouris, G.; Mavrikios, D.; Papakostas, N.; Mourtzis, D.; Michalos, G.; Georgoulias, K. (2009). Digital manufacturing: history, perspectives, and outlook, Proceedings of the Institution of Mechanical Engineers, Part B: Journal of Engineering Manufacture, Vol. 223, No. 5, 451462, doi:10.1243/09544054JEM1241

[5] Belaid, R.; T'kindt, V.; Esswein, C. (2012). Scheduling batches in flowshop with limited buffers in the shampoo industry, European Journal of Operational Research, Vol. 223, No. 2, 560-572, doi:10.1016/j.ejor.2012.06.035

[6] Aloini, D.; Dulmin, R.; Mininno, V. (2012). Modelling and assessing ERP project risks: A Petri Net approach, European Journal of Operational Research, Vol. 220, No. 2, 484-495, doi:10.1016/j.ejor.2012.01.062

[7] Dai, Q. Y.; Zhong, R. Y. (2009). Real-time interface between MES and SAP based on middleware, $3^{\text {rd }}$ International Conference on Anti-counterfeiting, Security, and Identification in Communication (2009 ASID), Hong Kong, 54-57

[8] Berlec, T.; Potocnik, P.; Govekar, E.; Starbek, M. (2010). Forecasting lead times of production orders in SME's, Iranian Journal of Science and Technology, Transactions B: Engineering, Vol. 34, No. B5, 521-538

[9] Onosato, M.; Iwata, K. (1993). Development of a virtual manufacturing system by integrating product models and factory models, CIRP Annals - Manufacturing Technology, Vol. 42, No. 1, 475-478, doi:10.1016/S0007-8506(07)62489-5

[10] Debevec, M.; Perme, T.; Noe, D. (2004). Decision making process in virtual manufacturing regarding human resources, IFAC Multitrack Conference on Advanced Control Strategies for Social and Economic Systems, Vienna, 173-178

[11] Debevec, M.; Perme, T.; Noe, D. (2006). A virtual manufacturing system for tool-making companies, International Journal Automation Austria, Vol. 14, No. 1, 1-12

[12] Krajnc, M.; Dolsak, B. (2013). Computer and experimental simulation of biomass production using drum chipper, International Journal of Simulation Modelling, Vol. 12, No. 1, 39-49, doi:10.2507/IJSIMM12(1)4.223 
[13] Kocisko, M.; Novak-Marcincin, J.; Baron, P.; Dobransky, J. (2012). Utilization of progressive simulation software for optimization of production systems in the area of small and medium companies, Technical Gazette, Vol. 19, No. 4, 983-986

[14] Zavbi, R.; Benedicic, J.; Duhovnik, J. (2010). Use of mixed academic-industrial teams for new product development: delivering educational and industrial value, International Journal of Engineering Education, Vol. 26, No. 1, 178-194

[15] Ostojic, G.; Stankovski, S.; Vukelic, D.; Lazarevic, M.; Hodolic, J.; Tadic, B.; Odri, S. (2011). Implementation of automatic identification technology in a process of fixture assembly/disassembly, Strojniski vestnik - Journal of Mechanical Engineering, Vol. 57, No. 11, 819-825, doi:10.5545/sv-jme.2010.131

[16] Gomes, J. H. F.; Salgado Jr., A. R.; de Paiva, A. P.; Ferreira, J. R.; da Costa, S. C.; Balestrassi, P. P. (2012). Global criterion method based on principal components to the optimization of manufacturing processes with multiple responses, Strojniski vestnik - Journal of Mechanical Engineering, Vol. 58, No. 5, 345-353, doi:10.5545/sv-jme.2011.136

[17] Mandic, V.; Eric, D.; Adamovic, D.; Janjic, M.; Jurkovic, Z.; Babic, Z.; Cosic, P. (2012). Concurrent engineering based on virtual manufacturing, Technical Gazette, Vol. 19, No. 4, 885892

[18] Iacob, R.; Popescu, D.; Mitrouchev, P. (2012). Assembly/disassembly analysis and modeling techniques: A review, Strojniski vestnik - Journal of Mechanical Engineering, Vol. 58, No. 11, 653-664, doi:10.5545/sv-jme.2011.183

[19] Wenzel, S.; Jessen, U.; Bernhard, J. (2005). Classification and conventions structure the handling of models within the Digital Factory, Computers in Industry, Vol. 56, No. 4, 334-346, doi:10.1016/j.compind.2005.01.006

[20] Heizer, J. H.; Render, B. (2001). Operations Management, Prentice Hall, Upper Saddle River

[21] Starbek, M.; Kusar, J. (2010). Production Planning and Control - Templates of Lectures, University of Ljubljana, Faculty of Mechanical Engineering, Ljubljana

[22] Zvokelj, J.; Jez, M.; Kosec, L.; Marek, E.; Kuzman, K.; Puhar, J.; Muren, H.; Prosenc, V.; Kolar, D.; Noe, D.; Sebenik, A. (1998). Mechanical Technology Handbook $\left(7^{\text {th }}\right.$ ed.), Tehniska zalozba Slovenije, Ljubljana

[23] Peterson, L. J. (1981). Petri Net Theory and the Modeling of Systems, Prentice-Hall Int., Englewood Cliffs

[24] Zeigler, B. P.; Praehofer, H.; Kim T. G. (2000). Theory of Modeling and Simulation (2 ${ }^{\text {nd }}$ ed.), Academic Press, San Diego

[25] Raczynski, S. (2012). Semi-discrete events and models in categorical language, International Journal of Simulation Modelling, Vol. 11, No. 2, 89-96, doi:10.2507/IJSIMM11(2)3.203

[26] Bangsow, S. (2010). Manufacturing simulation with Plant Simulation and Simtalk: Usage and Programming with Examples and Solutions, Springer-Verlag, Berlin 